\title{
Decolonizing Healing Through Indigenous Ways of Knowing
}

\author{
Miranda Field
}

The field of psychology is embarking on a process of interrupting the historical colonial cycle of harm and beginning to work with and alongside Indigenous communities to understand the healing journey (Drees, 2013). Understanding the healing journey provides a foundation for both those who seek and guide healing. As a society, disconnection with the land influenced how psychology teaches those who guide healing, the practices the field establishes as evidenced-based, and what elements contribute to positive outcomes. Exploring healing from a decolonizing perspective provides insight into the essential understanding where learning and healing coexist along this journey. Researchers, mental health service providers, and educators alike move towards acknowledging that challenging and displacing hegemonic Western knowledge systems is required to engage and enable multiple forms of literacy and knowledge to coexist (Kermoal \& Altamirano-Jimenez, 2016). This work is not possible without the guidance of Indigenous communities, ensuring that healing is engaged in a strength-based, ethically responsible manner and for those guiding healing, an individual process of decolonizing Western psychology practices can begin.

To better support trajectories of decolonizing practices in psychology, this chapter aligns with the Truth and Reconciliation of Canada (TRCC) Calls to Action (2012); specifically, Call to Action (Legacy, Health) 22, which calls upon "those who can effect change within the Canadian health-care system to

M. Field ( ()

University of Regina, Regina, SK, Canada

e-mail: mirandafield@uregina.ca

(C) The Author(s) 2022 
recognize the value of Aboriginal healing practices and use them in the treatment of Aboriginal patients in collaboration with Aboriginal healers and Elders where requested by Aboriginal patients" (TRCC, 2012). Acknowledging the notion that mental health healing may not occur without learning, and vice versa, shifts the paradigm to one where healing and learning coexist through meaningful relationships.

This chapter seeks to answer the call put forward by McGinnis et al. (2019), which calls on mental health practitioners and educators to recognize, support, and incorporate Indigenous knowledge systems in to practice and to consider the ethical implications of integrating and supporting Indigenous ways of knowing into current psychology practice. Through decolonizing land-based healing experiences and drawing on my personal journey-as an educator trained in psychology - I seek to integrate lived experience with supporting academic literature to provide an understanding of the historical, relational disconnection from land. Through Indigenous ways of knowing, the field of psychology can begin to decolonize individual practice and begin to integrate traditional ways of healing into current practice and embark in the process of interrupting the historical colonial cycle of harm. A foundational understanding within decolonizing psychology is understanding relationships through Indigenous ways of knowing and being. The personal journey is the beginning of reconnecting relationships through learning and healing.

I acknowledge the ways in which my upbringing as a European-descent Christian from rural Canada has a foundational influence on how I see myself, my community, and my world. I have dedicated friendships, education, and travel to allow myself the opportunity to broaden my understanding of the world and those around me. I understand and acknowledge that I do not know everything there is to know about any topic and seek support and further understanding in many areas. My network of personal and professional relationships continues to grow as I seek ongoing and continued support, which establishes a foundational network which I can draw upon when professional guidance and additional knowledge is required.

I acknowledge my minimal lived experience with oppression, racism, discrimination, and stereotyping and understand that my foundation is built around my world (growing up and now) being situated among the dominant ethnicity, culture, and belief systems of my surroundings. I continue to seek support, guidance, understanding, and patience from those knowledgeable in education and health care practices. I seek to engage in decolonized Indigenous understandings in areas from academia to land-based healing.

My training in both education and psychology has been greatly influenced by legally defensible writing and not that of nuance or publicized self-reflection. To decolonize my practices and understanding in psychology, I must disrupt the colonial influences of my foundation and embrace Indigenous ways of knowing and connecting to these lands. By acknowledging my settler influences and teachings, exploring Indigenous worldviews and the interconnectedness to wellness, and engaging in strength-based approaches guided by Indigenous communities, I have initiated personal and professional steps towards reconciliation. 


\section{A Path of Decolonizing Healing Through LEARNINg FROM THE LAND}

Indigenous Peoples have lived for thousands of years in harmony with the land, where deep spiritual connections to the land impact overall health and wellbeing (Alt, 2017; Kingsley et al., 2013). Through colonial disruptions, Indigenous Peoples experienced and continue to experience a disconnect from traditional ceremonies, traditional medicines, and traditional land uses. To connect further, McGinnis et al. (2019) bring attention to the impact of colonialization through the fragmenting of relationships among humans and more-than-humans. Colonization has influenced the detachment of traditional connections and relationships with humans, plants, animals, and the land (Elder B. McKenna, personal communication, May 4, 2019). The deep connections include both learning and healing from and with the land. The process of decolonizing healing involves reconnecting and engaging with the land to situate healing and learning. This chapter will operate with the following definitions offered by Indigenous scholars and teachers:

Styres (2019) defines decolonizing as "an unsettling process of shifting and unraveling the tangled colonial relations of power and privilege" (p. 30). Furthermore, Linda Tuhiwai Smith (2012) provides guidance on the careful consideration and critical thinking of each act of reading, writing, and research one partakes in when engaging with decolonization. Contrary to many thoughts on decolonization, Smith explains that:

Decolonization, however, does not mean and has not meant a total rejection of all theory or research or Western knowledge. Rather, it is about centering [Indigenous] concerns and world views and then coming to know and understand theory and research from [Indigenous] perspectives and for [Indigenous] purposes. (p. 4l)

From an Indigenous perspective, this healing journey has no definite beginning-it is not linear. It is based in meaning-making and relationships along the journey. The field of psychology may begin to move away from pathologizing healing to a strength-based healing process with this understanding when the focus shifts to relationships; relationships with self, relationships with community, relationships with the more-than-human, and relationships with the land. Elder Alma Poitras shares that from an Indigenous perspective, healing incorporates more than the physical recovery (personal communication, May 4, 2019). Indigenous healing includes the physical, spiritual, emotional, and mental aspects of one's being, which includes the use of ceremony and traditional medicines. Western medical practices have incorporated physical modalities, and Western psychology practices have incorporated emotional, mental, and spiritual healing modalities. From an Indigenous perspective, physical, emotional, mental, and spiritual healing exists through relationships which occur alongside the healing journey. 
Learning is often understood as the acquisition of knowledge or skills through experience, study, or by being taught. But as Indigenous teacher Dustin Brass shares:

If [Indigenous people] go back to [their] roots and we look at where education started for us as Indigenous people, it interacted with the land. . . The basis of the education is delivered through the land. It's a way to interact with learning from the land, learning from the environment, the things that surround us. (Blue Sky, 2020)

Centering Indigenous voices and definitions of healing work to decolonize the Western understanding of the healing journey. The definitions reinforce that the land, relationships, and spiritual connections are essential to understanding the healing and learning journeys for Indigenous peoples.

The following chapter is informed by my personal journey of decolonized land-based healing through learning experiences and supporting literature. This integration intends to illuminate the historical influence of human's disconnection with the land through articulating the experiential relationships. Through my personal learning journey via decolonizing practices, it is apparent that healing and learning coexist through engagement with the land.

\section{LEARNing AND HeALINg From the LAND}

The journey of healing begins with acknowledging a crisis - a crisis in the current practice of psychology and Indigenous Peoples (Johnston Research, 2010). Throughout colonial history, Indigenous peoples have not been given the opportunity to heal with dignity through their Indigenous ways of knowing and being (Raphael, 2018). To begin the journey of decolonization is to acknowledge our collective history. If it is called upon to integrate Indigenous ways of knowing into the field of psychology, an overall understanding of and critical engagement with current psychology practices must be present. Many current psychology practices are grounded in the Western psychology which refers to psychology influences of Europe and were established as the normative behaviours all cultures were to be judged and examined against. Western psychology integrates ideals of colonial cultures-explorers, conquerors, and settlers-where the goals of the perceived dominant culture enforced their policies and processes over the people (Raphael, 2018). Behaviours and views towards self, community, more-than-human, and land varied greatly and continue to contribute to a historical colonial cycle of harm.

Jordan (2015) shares the historical work of Levy-Bruhl and Jung, which describes how "Indigenous peoples do not distinguish themselves sharply from the environment, believing that what went on outside also went on inside of self" (p. 17). This exemplifies how the natural environment and Indigenous peoples are interwoven. "It is a culture so intrinsically linked to the land that what the [Indigenous peoples] saw (and still see) was not an environment 
with different geographical aspects, but a profoundly metaphysical landscape capable of expressing their deepest spiritual yearnings" (Jordan, 2015, p. 70). This interwovenness includes physical, emotional, mental, and spiritual wellness and provides affirmation that the natural environment is imperative for Indigenous wellness and healing.

Each human has experiences with the land, whether they recognize or acknowledge them as valid (Ball, 2013). The beginning of awareness is to explore and acknowledge each experience with, on, and within the natural environment-the land. These interactions with nature are important in our relationship to nature and to our healing (Jordan, 2015). Jordan continues that "it is through the presence of the natural world that the therapeutic process is facilitated; nature in this sense acts as another presence which both guides and provokes the therapeutic work" (p. 50). This awareness is not only for those receiving treatment, but for those providing support throughout the healing process.

\section{Building on Strengths of Relationships}

McGinnis et al. (2019) build upon previous literature which promotes the requirements of strength-based healing approached when working with Indigenous peoples. With the understanding that postmodern approaches move away from pathologizing people and move towards discovering an individual's strengths and connections, solutions are created in the present and in the future (Corey, 2016). Indigenous approaches are distinctly different from postmodern approaches but share strength-based foundations of individuals creating meaning in their lives through relationships. Strength-based approaches include connections to self, community, more-than-human, and the land and promote a balanced care approach which includes physical, emotional, spiritual, and mental healing. Strength-based approaches are clientcentered and include client choice, user-center environments for the client and families, and remained focused on the relationship (Alt, 2017; Elder A. Poitras, personal communications, May 4, 2019).

The continued integration of strength-based approaches requires an understanding of the social and cultural contexts of behaviour. Viewing behaviour and individual actions through this lens, assists in moving towards the present and future without situating solely in the past. Clients are not to blame for their problems; rather they are involved in creating solutions in moving forward in a positive direction (Corey, 2016). Stories assist the client with honouring their unique journey, both socially and culturally, and anchor this understanding in the physical, emotional, mental, and spiritual experiences within their story (Archibald et al., 2019).

Within healing processes, reciprocal mutual relationships focus on the meanings given to experiences rather than focusing primarily on the biological influences of disorders. This lens provides an important understanding of 
the experiences of the client, which impacts the therapeutic process (Jordan, 2015).

\section{Relationship With Self}

To further articulate my journey of awareness, I share a story of my journey learning alongside Indigenous healers and how, through experiences such as this, I embarked on my journey of awareness and understanding of Indigenous ways of knowing. My personal journey of reconnecting with the land was solidified in a retreat which served as a foundational period where I actively engaged in addressing my own worldview and opened myself to exploring Indigenous connections to the land:

I had the opportunity to participate in an autumn retreat at Wanuskewin (the name wanuskewin means gathering place), located in Saskatchewan, Canada. Wanuskewin is known to be a deeply spiritual place where, for more than six thousand years, Indigenous peoples of the Northern Plains gathered to hunt buffalo, gather medicine and food, and escape the winter winds. Archaeological dig sites located at Wanuskewin have been dated to before the time of the Egyptian pyramids, and artifacts such as tipi rings, pottery fragments, plant seeds, and projectile points give insight into the ancient societies (Wanuskewain Heritage Park Authority, 2020).

This retreat was my first immersive experience which joined Elders, Indigenous students, non-Indigenous students, and researchers through workshops, lectures, and speakers, which were held in conjunction with hands-on land activities. Traditional foods, nehiyawak (Plains Cree) language lessons, snaring, bow shooting, beading, plant and medicine walks, campfires, sleeping in tipis, and archeology hikes were activities I took part in during this immersion retreat.

An archeology student gifted her time to the retreat participants to share her current work located at Wanuskewin. We began our walk into the small valley on the warm autumn evening. The leaves had begun to change colours from green to golden brown, orange, and red; the grass was damp at our feet. As we descended into the valley nearing sunset, we followed the winding path in and among the bushes and trees, over the creek, and came upon the open clearing. In the center of this clearing sat a blue tarp and wooden pit cover. As the archeology student opened the wooden cover, she shared stories of the discoveries of ancient tools, toys, and cooking ware. What I was not aware of in the stories she shared, was the ethical application of archeology digs. To learn of the ethics surrounding excavation, to leave items along the edges untouched, illuminated the great respect that occurs within this practice. There is great respect for sites that are explored and are specific rules in place to ensure voyeuristic exploration does not occur. Even when these items may benefit or further our understanding of the ancient peoples, these rules apply.

As I took part in the gathering of medicines, grasses, and berries alongside Elders I listened to them; the teachings continue to only take a little and leave 
a lot. I take these teachings into practice, and with respect to the teachings about the animals and their need for food, these support sustained growth of the plants and animals. The notion of not taking all of a plant is understandable in the literal sense. If you take it all, it will be gone (Kimmerer, 2013). But, to observe and practice these understandings offers a profound respect to the teachings offered. This immersion experience was my first dedicated step in actively engaging with the land.

As researchers, scholars, and teachers, the want to know more is always present. My personal journey is no different. To be ok with not knowing everything is a teaching in and of itself. To know it is not your place, or your story must be understood and accepted.

Gaining awareness of how our inner processes can be represented in relation to our outer reality can be facilitated through focusing on the land (Jordan, 2015). Gaining awareness of self is essential and being in the natural environment facilitates healing for both the practitioner and the client. Elder Vee Whitehorse shares that "wisdom can not be given, it has to be experienced on your own" (personal communication, May 11, 2019). Through this, individuals are honoured as the experts of their own lives. The awareness that is gained along this journey is based on the understanding that the individual is not the problem; the problem is the problem (Corey, 2016), and knowing this works towards building healing capacity, which is facilitated through learning about one's self.

\section{Relationships With THE COMmunity}

Healing in isolation is difficult; clients heal with the support of their community (Alt, 2017). Relationships with other communities and people who enjoy wellness and health and who have connections to others, nature, and the spiritual world have been indicators of individual healing (Canadian Collaborative Mental Health Initiative, 2006). These relationships create collaborative dialogues where solutions are co-created (Corey, 2016). Collaborative dialogues establish clear and observable goals which work towards creating a self-identity based in culture, individual strengths, and community resources to address present and future concerns. Incorporating Indigenous ways of knowing and being into the healing journey may move forward through Marsh et al.'s (2016) recommendation for future studies to include and focus on the importance of collaboration between mainstream and Indigenous healers.

\section{Relationships with the More-Than-Human}

As a white settler, I have begun to establish and reflect on my personal connections to healing and learning from the land. I acknowledge I will never be able to comprehend the extent of Indigenous peoples' interconnection to the land, but I seek to ethically engage my personal and professional practice. 
The idea of a neutral space exists when working in the natural world; it operates as a space where neither the client nor therapist own or control the space (Berger, 2006; Jordan, 2015). A neutral space facilitates the concept of a transitional space which "exist[s] within and between geographical and relational 'spaces,' and between mind and nature" (Jordan, 2015, p. 54). This transitional space integrates Indigenous ways of knowing and being-the transition space represents the spiritual connection. Taking time to observe, listen, and engage in the natural environment is the natural way of healing (Elder A. Poitras, personal communication, May 4, 2019) and provides space to connect with one's self, one's community, the more-than-human, and the land.

My personal experience with transitional space occurred while observing the join up of a Curly Horse and a human. Curly Horses are considered Indigenous to North America and in this experience, the Curly Horses are participants in Equine Assisted Learning and Animal Assisted Therapy. This experiential learning opportunity is grounded in non-violent, trust-based partnerships between human and horses. A join up refers to a bonding method during the first formal time a horse interacts with a human and through this process is where I was able to observe this transitional space. A space where the human and more-than-human create a connection, a bond, that is true and real. This bond between horse and human occurs through body language, body positioning, and eye contact and this connection invites the horse to approach.

To observe the respect and trust that is required for any form of connection to occur between human and horse is difficult to describe. To see this in person is a piece of indescribable beauty. The most significant observation from my experience with Curly Horses is the human allowing and providing the opportunity to the animal the option to retreat (to move away physically and emotionally) when overcome. Not only offering the retreat but honouring the retreat. The relationship is built upon trust and respect that allows space when it is needed, but to always welcome them back when they are ready. This is a teaching which honours the relationship and the spirit of both humans and more-than-humans.

In contrast to many Western notions of land, Indigenous understandings situate spirit as a central component of knowing and recognizes the spirit's innate existence in all life forms (Dell et al., 2011). To understand the connection between human and horse is to understand the spirit works in relation with the natural physical environment - animate and inanimate-and is central to Indigenous ways of knowing. Where spiritual and physical realities meet is described as a space where spiritual exchange occurs (Dell et al., 2011). This space is described within First Nations, Inuit, and other Indigenous languages throughout the world. In Dell et al. (2011), Te Pou references a concept of the Samoan peoples of the Pacific Islands. The concept of "Va" refers to the "space between", which maintains respect to scared space, harmony, balance, and the importance of relationships between our physical, spiritual, emotional, and mental dimensions. Te Pou elucidates that "relationships are not unidirectional, but mutually linked and reciprocal, and the space between, is not space 
that separates, but space that relates" (Dell et al., 2011, p.9). The foundation to individual and communal healing is formed upon the understanding that space recognizes the culture and creates meaning which is informed by spirit (Dell et al., 2011).

\section{RELATIONSHIPS WITH THE LAND}

Many Indigenous worldviews express that all must live in harmony with nature, which entails taking care of the earth-and not controlling it (CCMHI, 2006). Jordan (2015) believes "an understanding of the human problem of need and dependency can help us more fully understand why we... have developed an insecure, avoidant and ambivalent relationship to nature and the planet" (p. 52). Within Indigenous cultures the natural environment, including plants, animals, and the land, has played a primordial role within traditional knowledge, ceremony, and healing (Gendron et al., 2013). Generations of Elders, adults, youth, and children have and continue to spend time learning with and from the land.

Experiential approaches to learning and healing build upon strengths of Indigenous ways of knowing and being in relation with the land (Greenwood et al., 2018). Having opportunities where one can authentically interact with the land begin to initiate healing effects. Elder Alma Poitras (personal communications, May 4, 2019) shares that that natural way of healing includes seeing, hearing, touching, smelling, and tasting the natural environment. Through these acts, Elder Alma guides those to ask: What I am supposed to learn from this? My understanding in this is where meaning-making interconnects with learning and healing.

Exploring current mental health practice, design, and experiences creates discussions around how the land is or is not integrated into healing practices. In psychology, what do we value as important along the healing journey and how does this impact our clients? Along my journey, the interconnection between healing and learning became evident when reflecting on how my own children see and experience nature. Here I will share a personal story of observations during my children's play.

Endless piles of rocks and sticks. Wherever we travel, the park, the school, the driveway, the beach, or across Canada, little pockets return full of sticks and stones. These objects caught my children's eyes in a way that my own eyes could not. The colours, the sparkles, the flecks, and patterns along with the bends, twists, and bumps become an irresistible desire. These objects become items of barter and negotiation to determine how many of these treasures will be allowed to make the journey to our home. It is easy to dismiss these perceived treasures as such. With the dirt, sand, and bugs, it is easy to ask for them to be tossed aside and left where they are. But to the children, these are the finest of treasures that have been found on the most enduring of archeological digs. These sticks and stones are the tokens, the glorious prizes of the adventure that was had. To the children, sticks and stones represent their 
accomplishments, a sense of pride and a sense of wonder to the events of the day. When we, as adults, quickly dismiss these treasures as dirty and not worthy, we begin to tell our children that what they see as valuable is not. What they work hard for is not important. And if it is not pleasing to an adult, it does not matter. These sticks and stones, as small as they might seem, teach us lessons of value and difference, and as adults, we very quickly exchange what is valuable, what is worthy, and what is to be treasured.

\section{Building Healing Through Learning}

The healing journey is not intended to be linear. Decolonizing personal and professional practice involves acknowledging where the crisis is, moving from awareness to understanding, and organizing these understandings into action. Similar to the healing journey, the decolonizing journey is not linear and involved a process of learning. To clearly identify my personal learning and healing experiences, Ritchhart et al. (2011) present a starting point to make thinking visible and to articulate the learning process. A numbered list highlights my journey of identifying the steps which I have taken to describe how my understanding is developed (Ritchhart et al., 2011).

\section{Healing Through Learning About Self}

If healing occurred with my relationship to self, then I speak to that healing as being assisted by decolonizing learning from the land. Along a private walk during the retreat, I came upon the most beautiful old rocks covered in various kinds of moss. I wanted to know their story, their purpose. This experience allows me to ( 1 ) observe closely and describe what is there (Ritchhart et al., 2011). Sitting, listening, feeling, and smelling - those were the stories I was given. Through this, I begin (2) building explanations and interpretations (Ritchhart et al., 2011) of what I have been given. Although, being OK with not knowing has to occur. Reflection time allows for the individual to be present in the experiences and the space to learn about and from the land. Unrestricted reflective time fosters additional focus for connections, meaningmaking, and clarity. Knowing there may not be answers, or connections may not be evident, allowed me to reduce my feelings of nervousness and insecurities towards the need for answers. The acceptance of the not knowing brings comfort in the healing process.

\section{Healing Through Learning About Community}

If healing occurred to my relationship with community, then I speak to that healing as being assisted by decolonizing learning from the land. Within the Indigenous communities (students, scholars, peers, Elders) I have been working alongside, many have granted me the gift of acceptance within the community. To be welcomed within a community has reignited my interest 
in many topics where I felt as though I could not continue. Community members have aided in my understanding and acceptance of my own physical, emotional, mental, and spiritual limits - both professionally and personally. Through (3) reasoning with evidence (Ritchhart et al., 2011), the community has assisted me in strengthening my connections to the community. I am more confident in who I am and where I belong in this community. These strengthened relationships have supported and guided me through the process of decolonizing my personal and professional practice. I am more confident in the work I partake in and more willing to accept the challenges life offers.

\section{Healing Through Learning About the More-Than-Human}

If healing occurred through my relationship with the more-than-human, then I speak of this healing as being assisted by decolonized learning from the land. While observing Curly Horses, it was evident trust was an essential component of the human and more-than-human relationship. This relationship requires respecting the spirit and journey while establishing safe forms of communication. (4) Making connections (Ritchhart et al., 2011) between how the Curly Horses and humans form relationships, Nadasdy (2007) draws on literature from anthropology which chronicles Indigenous world views regarding human and more-than-human relationships as reciprocal. This reciprocation involves both learning and healing existing and moving through the space between. Understanding that the spirit is a central component of knowing, having practitioners acknowledge and recognize the spirit's innate existence in all life forms is essential to integrating Indigenous ways of knowing and being into current practice.

\section{Healing Through Learning About the Land}

If healing occurred with my relationship with the land, then I speak of this healing as being assisted by decolonized learning and active engagement with the land. The experience of observing my own children and their interactions with the land encourages the (5) consider[ation of] different viewpoints and perspectives (Ritchhart et al., 2011) and allows all to analyze why these items, topics, and relationships are of importance to the individual. This time allows space to accept the unknown or understood and through trust and respect, honour and value the significance of these relations. Fostering our relationship with the land is the act of healing in relation (A. McGinnis, personal communication, May 11, 2019). A sense of pride is felt when I observe the unadulterated wonder and joy my children have when interacting with the land. These relationships have created an ongoing reciprocation involving both learning and healing existing and moving through the space between. 


\section{HONOURING THE JOURney}

The final step to making my thinking visible is step (6), capturing the heart and forming conclusions (Ritchhart et al., 2011). To decolonize healing is to embrace the notion that healing and learning coexist through relationships with the land along the journey. Within the journey lies a reciprocal, interwoven relationship between learning about self, learning about the community, learning about the more-than-human, and learning about the land. Through acknowledging and understanding our colonial past and taking action to begin decolonizing ourselves, actively engaging in this process will facilitate an open space to promote and integrate Indigenous ways of healing and learning into ethical psychology practices. Through these relational experiences, the space between facilitates healing effects through spiritual connections for both the practitioner and the client and begins to address the historical relational disconnect with the land.

It remains an ethical responsibility for the field of psychology to include, incorporate, and provide opportunities for the integration of the natural environment to support Indigenous ways of knowing and being in current practice (Elder A. Poitras, personal communication, May 4, 2019). The journey for practitioners begins with acknowledging the crisis in our relationship with the natural environment. The journey continues through bringing awareness to our understandings and teachings about the world, and through the ownership of our ways, practitioners can view the natural environment as actively supporting Indigenous wellness.

Through this perspective shift it is possible to release colonial influences. Utilizing a strength-based understanding the field of psychology can practice in collaboration with Indigenous communities to incorporate Indigenous ways of knowing, working with and within the natural environment, into our practice. When practitioners begin on this journey of meaning-making, it may contribute to the reconciliation process of decolonizing individual practice, understanding, and move towards authentically supporting, respecting, and integrating Indigenous ways of knowing and being into the therapeutic process.

Building healing capacity through learning elucidates the understanding of the past, the needs of the present, and lays foundations for the future to work towards restoring integrity and prompting ethical balanced care. In confidence, healing with dignity may be facilitated through relationships with self, community, more-than-human, and the land. McGinnis et al. (2019) eloquently concludes that "reconciliation across Western and Indigenous contexts requires learning to work together with the more-than-human world and developing ethical spaces for health research in which holistic wellness is appreciated and understood in the context of all our relations" (p. 1). 


\section{REFERENCES}

Alt, P. (2017). Sacred space and the healing environment. Annuals of Palliative Medicine, 6(3), 284-296.

Archibald, L., Lee-Morgan, J., \& De Santolo, J. (2019). Decolonizing research: Indigenous storywork as methodology. Zed Books.

Ball, N. (2013). Just do it: Anishinaabe culture-based education. Canadian Journal of Native Education, 36(1), 36-58. https://login.libproxy.uregina.ca:8443/login? url=https://search-proquest-com.libproxy.uregina.ca/docview/1523947533?acc ountid=13480.

Berger, R. (2006). Beyond words: Nature-therapy in action. Journal of Critical Psychology, Counseling and Psychotherapy, 6(4), 195-199.

Blue Sky. (2020, January 9). Former Balfour Collegiate teacher lauds benefits of landbased education. CBC News. https://www.cbc.ca/news/canada/saskatchewan/for mer-balfour-collegiate-teacher-lauds-land-based-learning- 1.5420882 .

Canadian Collaborative Mental Health Initiative. (2006). Pathways to healing: A mental health guide for First Nations people. Canadian Collaborative Mental Health Initiative.

Corey, G. (2016). Theory and practice of counseling and psychology. Cengage Learning.

Dell, C., Chalmers, D., Bresette, N., Swain, S., Rankin, D., \& Hopkins, C. (2011). A healing space: The experiences of First Nations and Inuit youth with equine-assisted learning. Child Youth Care Forum, 40, 319-336. https://doi.org/10.1007/s10 566-011-9140-z.

Drees, L. (2013). Healing histories: Stories from Canada's Indian hospitals. The University of Alberta Press.

Gendron, F., Bourassa, C., Cyr, D., McKenna, B., \& McKim, L. (2013). The medicine room: A teaching tool for elders and educational opportunity for youth. First Nations Perspectives, 5(1), 83-97.

Greenwood, M., de Leeuw, S., Lindsay, N., \& Reading, C. (2018). Determinants of Indigenous peoples' health in Canada: Beyond the social. Canadian Scholars' Press.

Johnston Research. (2010). Waawiyeyaa evaluation tool. https://www.johnstonrese arch.ca/the-waawiyeyaa-evaluation-tool/.

Jordan, M. (2015). Nature and therapy: Understanding counselling and psychotherapy in outdoor spaces. Routledge.

Kermoal, N., \& Altamirano-Jimenez, I. (2016). Living on the land: Indigenous women's understanding of place. AU Press.

Kimmerer, R. W. (2013). Braiding sweetgrass: Indigenous wisdom, scientific knowledge, and the teachings of plants. Milkweed Editions.

Kingsley, J., Towsend, M., Henderson-Wilson, C., \& Bolam, B. (2013). Developing an exploration framework linking Australian aboriginal peoples' connection to country and concepts of well-being. International Journal of Environmental Public Health, 10, 678-698. https://doi.org/10.3390/ijerphl0020678.

Marsh, T., Cote-Meek, S., Najavits, L., \& Toulouse, P. (2016). Indigenous healing and seeking safety: A blended implementation project for intergenerational trauma and substance use disorders. The International Indigenous Policy Journal, 7(2). https:// doi.org/10.18584/iipj.2016.7.2.3.

McGinnis, A., Kincaid, A., Barett, M., Ham, C., \& Community Elder Research Advisory Group. (2019). Strengthening animal-human relationships as a doorway to 
Indigenous holistic wellness. Ecopsychology, 11(3), 162-173. https://doi.org/10. 1089 /eco.2019.0003.

Nadasdy, P. (2007). The gift in the animal: The ontology of hunting and humananimal sociality. American Ethnologist, 34(1), 25-43. https://www.jstor.org/sta ble/4496783.

Raphael, D. (2018). The social determinants of health of under-served populations in Canada. In A. Arya \& T. Piggott (Eds.), Under-served: Health determinants of Indigenous, inner-city, and migrant populations in Canada (pp. 23-38). Canadian Scholars.

Ritchhart, R., Church, M., \& Morrison, K. (2011). Making thinking visible: How to promote engagement, understanding, and independence for all learners. Jossey-Bass.

Smith, L. T. (2012). Decolonizing methodologies: Research and indigenous peoples. Zed Books.

Styres, S. (2019). Literacies of land: Decolonizing narratives, storying, and literature. In L. Smith, E. Tuck, \& W. Yang (Eds.), Indigenous and decolonizing studies in education: Mapping the long view (pp. 24-37). Routledge.

Truth and Reconciliation Commission of Canada (TRCC). (2012). Call to Action (Legacy, Health).

Wanuskewain Heritage Park Authority. (2020). Wanuskewain. https://wanuskewin. com/.

Open Access This chapter is licensed under the terms of the Creative Commons Attribution 4.0 International License (http://creativecommons.org/licenses/by/4.0/), which permits use, sharing, adaptation, distribution and reproduction in any medium or format, as long as you give appropriate credit to the original author(s) and the source, provide a link to the Creative Commons license and indicate if changes were made.

The images or other third party material in this chapter are included in the chapter's Creative Commons license, unless indicated otherwise in a credit line to the material. If material is not included in the chapter's Creative Commons license and your intended use is not permitted by statutory regulation or exceeds the permitted use, you will need to obtain permission directly from the copyright holder.

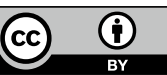

